\title{
O ensino das ciências sociais em saúde: entre o aplicado e o teórico
}

\author{
The teaching of social sciences in health: \\ between practice and theory
}

Nelson Filice de Barros ${ }^{1}$

${ }^{1}$ Departamento de Saúde Coletiva, Faculdade de Ciências Médicas,

Universidade Estadual de Campinas. R. Tessália Vieira de Camargo 126, Barão Geraldo. 13.083-887 Campinas SP Brasil. filice@fcm.unicamp.br

\begin{abstract}
The models of teaching social sciences and clinical practice are insufficient for the needs of practical-reflective teaching of social sciences applied to health. The scope of this article is to reflect on the challenges and perspectives of social science education for health professionals. In the 1950 s the important movement bringing together social sciences and the field of health began, however weak credentials still prevail. This is due to the low professional status of social scientists in health and the ill-defined position of the social sciences professionals in the health field. It is also due to the scant importance attributed by students to the social sciences, the small number of professionals and the colonization of the social sciences by the biomedical culture in the health field. Thus, the professionals of social sciences applied to health are also faced with the need to build an identity, even after six decades of their presence in the field of health. This is because their ambivalent status has established them as a partial, incomplete and virtual presence, requiring a complex survival strategy in the nebulous area between social sciences and health.
\end{abstract}

Key words Social sciences, Sociology of health, Teaching, Identity, Integration
Resumo Os modelos de ensino de ciências sociais e da clinica são insuficientes para as necessidades prático-reflexivas quando aplicados à saúde. $O$ objetivo deste artigo é refletir sobre os desafios e as perspectivas do ensino de ciências sociais para profissionais da saúde. Na década de 1950 iniciou-se o importante movimento de aproximação das ciências sociais com o campo da saúde, no entanto prevalecem relações de fraca credencial, devido: baixo status profissional dos cientistas sociais na área da saúde; localização pouco clara dos profissionais de ciências sociais no campo da saúde; pequena importância atribuída pelos estudantes às ciências sociais; reduzido número de profissionais e a colonização das ciências sociais pela cultura biomédica no campo da saúde. Dessa maneira, aos profissionais das ciências sociais aplicadas à saúde ainda é colocada a necessidade de construir uma identidade, mesmo após seis décadas de presença neste campo, pois sua condição ambivalente os tem fixado como presença parcial, incompleta e virtual, exigindo estratégia complexa de sobrevivência na fronteira entre as ciências sociais e a saúde.

Palavras-chave Ciências sociais, Sociologia da saúde, Ensino, Identidade, Integração 


\section{Introdução}

Este artigo resulta de uma "sociologia da prática"1-6 situada em uma "ambivalência"7,8. Em outras palavras, é um trabalho de apreensão do senso prático da docência na ação de teorização na interface entre o campo das Ciências Sociais e da Saúde.

Os modelos conhecidos de ensino de ciências sociais e da clínica são insuficientes para nossas necessidades, uma vez que priorizam exclusivamente ou o polo reflexivo ou o prático e nossa praxis exige métodos prático-reflexivos em diferente cenários formativos. De outra maneira, a questão que se coloca é: como garantir que um conceito sócio-historicamente construído não seja utilizado por profissionais de saúde como se fosse um insumo da sala de curativos?

Tenho colocado esta pergunta pedagogicamente para diferentes grupos de estudantes e profissionais de saúde para situar a diferença entre o conhecimento no campo das ciências sociais e da saúde. Parto das reflexões de Canguilhem, repetindo que a medicina não é uma ciência, mas um campo de aplicação de conhecimento científico, que incorpora práticas, procedimentos, conceitos e teorias. Segundo Zingerevit ${ }^{9}$, Canguilhem começou a cursar a medicina em 1936, quando já era professor de filosofia, e para o segundo "a medicina nos parecia e nos parece ainda uma técnica ou uma arte situada na confluência de várias ciências, mais do que uma ciência propriamente dita". Deste modo, afirma que a medicina não pode ser considerada uma ciência (epistéme), pois não existiria ou mesmo encontraríamos um real conhecimento conceitual de "ciência médica". Ainda segundo Zingerevit", em 1985 Canguilhem afirma em num colóquio internacional em Perúgia, Itália, que a racional "máquina de curar" pode ser pensada como une somme évolutive de sciences appliquées (uma soma evolutiva de ciências aplicadas).

Sigo a reflexão sobre a questão anterior apresentando uma imagem bastante presente para profissionais de saúde, situando-os em uma sala de curativos em que uma pessoa precisa ser tratada. Naquele instante, tomam-se os insumos necessários, como: álcool, algodão, anestésico etc., e realiza-se a intervenção sem a preocupação de construir o processo sócio-histórico relativo ao insumo. Porém, em um exercício compreensivo ou analítico de base social, cada um daqueles produtos faz parte de uma cadeia produtiva, podendo, portanto, ser tratado como uma mercadoria, que implica em relações de trabalho, regulamen- tações legais e simbólicas, referentes a cada contexto e cultura. Para concluir, abro o diálogo aprofundando sobre as implicações de usar conceitos e teorias sociais como insumo, ou sobre os efeitos de tratar uma ação social como algodão, uma vida como uma mercadoria. Porém, é necessário como cientistas sociais ensinando profissionais de saúde, também, perguntar: como garantir que o processo sócio-histórico dos insumos utilizados na saúde seja possível de ser construído mesmo por quem faz curativo?

O objetivo deste artigo é refletir sobre os desafios e as perspectivas tematizados nas questões anteriores sobre o ensino de ciências sociais para profissionais da saúde, a partir de um conjunto de constatações observadas na literatura especializada e pela experiência da docência para estudantes dos anos iniciais do curso médico e de enfermagem em diferentes universidades.

\section{Ciências sociais no campo da saúde: credencial e conhecimento}

O meu exercício de identificar defasagens entre o ideal e as várias formas de existência concreta compõe a ambivalência, das ciências sociais no campo da saúde, afinada com a perspectiva desconstrutora de Bhabha ${ }^{7}$. Em outras palavras, mesmo apontando hora por um, hora por outro, dos polos deste par formado pelas ciências sociais e as ciências da saúde, o foco é a ambivalência como "terceiro espaço" de enunciações, que acompanha a "assimilação de contrários" e pressagia a formação de uma cultura dos entre espaços. Porém, alerta Bhabha ${ }^{7}$, é preciso lembrar que o "inter" é o fio cortante da tradução e da negociação, o entrelugar, o terceiro espaço, que permite evitar a política da polaridade e emergir como os outros de nós mesmos. Assim, o entendimento da contradição vai distante e chega onde deve alcançar as ciências sociais na saúde, nenhum outro, senão o lugar insubstituível das relações sociais.

Para auxiliar a visualização das ambivalências das ciências sociais no campo da saúde apresento o Quadro 1, tomando as noções de credencial e conhecimento. A credencial, neste texto, não está associada às abordagens que ressaltam a "estratégia de fechamento social por parte das profissões, princípio monopolizador do mercado de trabalho, e responsável pelos privilégios que possuem na hierarquia ocupacional" ${ }^{10}$. Mas, como potência de existência ou um habitus em um campo de disputas, no sentido bourdiano ${ }^{1-4}$. Portanto, a credencial, neste caso, são as características dos cientistas sociais que habitam o cam- 
Quadro 1. Tipologias formadas a partir da credencial e do conhecimento das ciências sociais aplicadas à saúde.

\begin{tabular}{|c|c|c|}
\hline \multirow{2}{*}{ Credencial } & \multicolumn{2}{|c|}{ Conhecimento } \\
\hline & Muito & Pouco \\
\hline Forte & Forte credencial com muito conhecimento & $\begin{array}{l}\text { Forte credencial com pouco conhecimento } \\
>\quad \text { Graduação de Saúde Coletiva }\end{array}$ \\
\hline Fraca & $\begin{array}{l}\text { Fraca credencial com muito conhecimento } \\
\text { Draduações de cursos da saúde } \\
>\text { Pós-Graduação em Saúde Coletiva }\end{array}$ & $\begin{array}{l}\text { Fraca credencial com pouco conhecimento } \\
>\quad \text { Gestão do Sistema Único de Saúde }\end{array}$ \\
\hline
\end{tabular}

po da saúde com determinado quantum de capital técnico, cultural, simbólico e político. Por conhecimento entendo a produção de conceitos dentro de matrizes teóricas, bem como a produção de métodos e técnicas voltados para a pesquisa em saúde.

A célula que situa forte credencial e muito conhecimento representa um tipo ideal ${ }^{11}$ de inserção de cientistas sociais no campo da saúde. Dessa maneira, o ideal racionalmente esperado, após passadas mais de cinco décadas de trabalho e com uma tradição bem estabelecida internacionalmente no ensino, pesquisa e extensão acadêmica, é que o corpo de profissionais de ciências sociais exista com uma credencial forte - que se reproduza em relação aos valores e perspectivas - e com muito conhecimento - do ponto de vista da construção de matrizes teórico-conceituais -, criando uma tradição de pensamento. Portanto, muito conhecimento e forte credencial seriam os elementos da consagração dos cientistas sociais no campo da saúde em termos do complexo político-científico, porém esse lugar existe apenas no plano ideal.

Uma vez estabelecido este tipo ideal e a operação comparativa ideal-concreto pode-se compreender como os cientistas sociais se inserem, produzem e vivem a ambivalência no campo da saúde. Assim, a inserção destes profissionais no ensino de cursos de graduação e pós-graduação em saúde pode ser considerada de fraca credencial, sobretudo pela pequena participação em números absolutos nas instituições de ensino e pesquisa, e com muito conhecimento, principalmente pela quantidade das produções e potência desta produção ${ }^{12}$. Como se pode ver, esta célula traz duas formas de inserção e representa o maior número de cientistas sociais na saúde, pois o ensino é o lugar privilegiado de ingresso.
$\mathrm{Na}$ célula que situa forte credencial e pouco conhecimento habitam os cientistas sociais que ensinam nos cursos de graduação de saúde coletiva e seus correlatos, criados a partir do inicio da década de 2000. Caracterizam-se com forte credencial, por oferecerem disciplinas específicas de ciências sociais em dois ou três semestres dos cursos, porém com pouca produção de conhecimento, uma vez que não foi produzido, ainda, material específico de ciências sociais, com a força de um manual, segundo Kuhn ${ }^{13}$, voltada para as análises desse corpo no campo da saúde.

Por fim, a célula que apresenta fraca credencial e pouco conhecimento é habitada por homens e mulheres invisíveis, tanto do ponto de vista da legalidade quanto da legitimidade de sua participação no campo da saúde e contribuição técno-teórico-conceitual para o trabalho neste âmbito ${ }^{14}$.

A primeira tipologia dos profissionais da sociologia que trabalhavam com o tema da saúde foi criada em 1957 e ainda é bastante operativa, pois dividiu aqueles que se inseriram no campo da saúde e os que tomaram a saúde como objeto de pesquisa. Straus ${ }^{15}$ identificou-os como os profissionais "in" e "of", mostrando que assim se constituem visões e identidades de "insiders" e "outsiders". Uma consequência desta distinção, segundo o autor, é que o mesmo problema ganha dimensão e abordagem distintas conforme a inserção profissional.

Turner $^{16}$ revisitou a classificação de $\operatorname{Straus}^{15} \mathrm{e}$ concluiu que analisar questões de saúde estando inserido no campo produz não só análises diferentes, mas preocupações temáticas distintas nos níveis individual, social e societal. Assim, por exemplo, no primeiro nível, enquanto cientistas sociais no campo da saúde investigam comportamentos e crenças associados ao processo saúdedoença, aqueles que tomam temas do campo da 
saúde analisam o conhecimento médico. No nível social, os primeiros tendem a focar as causas sociais das doenças, enquanto os de fora do campo tendem a debater a dominância médica e a rivalidade interprofissional. No nível societal os cientistas sociais inseridos em instituições da saúde trabalham para melhorar a efetividade e eficiência de políticas de saúde, enquanto os que se inserem no campo das ciências humanas interessam-se mais pelo debate sobre a globalização e os sistemas nacionais de saúde.

A análise mais recente e bastante contundente da sociologia aplicada à saúde foi realizada por Michael Burawoy ${ }^{17}$. Seu propósito principal é construir o que chama de Sociologia Pública e para isso toma diferentes tipos de conhecimento sociológico, destacando: o conhecimento produzido por diferentes perspectivas do fazer sociológico; a coexistência dessas diferentes formas; e a orientação ético-política das diferentes "sociologias".

Não irei reproduzir todo o debate sobre a Sociologia Pública de Burawoy, mas apenas os aspectos fundamentais para as ciências sociais no campo da saúde. O autor desenvolveu 11 teses em favor do que denomina "sociologia pública”, conforme Schwartzman ${ }^{18}$, imitando Marx e gerando uma grande polêmica que ainda perdura. Considera-se que a mais importante e contenciosa é a décima primeira, pois recupera questões fundamentais da participação orgânica do intelectual na sociedade civil. No entanto, as outras teses também disparam importantes considerações para explicitar o potencial e os limites de cada um dos tipos de sociologia em relação a diferentes categorias do conhecimento e da participação social. Apresento o Quadro 2, construído por Braga e Burawoy ${ }^{19}$, cruzando tipos de conhecimento e tipos de sociologia.

Para o autor, o pensamento social tem duas matrizes orientadas para projetos distintos, pois aqueles que adotam a reforma social assumem o conhecimento em uma perspectiva instrumental, orientando-o para resolução de problemas sociais e, às vezes, sociológicos. Por outro lado, os profissionais que procuram compreender a ordem social, no seu jogo de oficialização e ocultamento dos fatos sociais, adotam a perspectiva reflexiva, orientada para o entendimento dos fins, tanto das premissas valorativas, como técnicas ${ }^{17-19}$.

Os dois tipos de sociologia identificada com o conhecimento reflexivo são a Sociologia Crítica e a Sociologia Pública, a primeira acadêmica, cumpre o papel de examinar as fundações explícitas-implícitas e normativas-descritivas dos programas de pesquisa da sociologia profissional, de forma que se define amplamente por sua oposição à sociologia profissional hegemônica ( $m a-$ instream). Em cada caso, a sociologia crítica tenta alertar a sociologia profissional dos vieses e silêncios através da construção de novos programas de pesquisa construídos em bases alternativas, colocando duas questões fundamentais: Sociologia para quem? e Sociologia para que?.

A Sociologia Pública, segundo Braga e Santana ${ }^{20}$, é extra-acadêmica e compreende genericamente um "estilo" de se fazer sociologia "engaja-

Quadro 2. Tipos de Conhecimento Sociológico e Tipos de Sociologia.

\begin{tabular}{|c|c|c|}
\hline Tipos de conhecimento & \multicolumn{2}{|c|}{ Tipos de Sociologia } \\
\hline $\begin{array}{l}\text { Instrumental } \\
\text { Conhecimento } \\
\text { Verificação } \\
\text { Legitimidade } \\
\text { Prestação de contas } \\
\text { Política } \\
\text { Patologia }\end{array}$ & $\begin{array}{l}\text { Sociologia Profissional } \\
\text { Teórico/empírico } \\
\text { Correspondência } \\
\text { Normas científicas } \\
\text { Aos pares } \\
\text { Interesse profissional } \\
\text { Autorreferencialidade }\end{array}$ & $\begin{array}{l}\text { Sociologia Para Políticas Públicas (Aplicada) } \\
\text { Concreto } \\
\text { Pragmática } \\
\text { Efetividade } \\
\text { Aos clientes } \\
\text { Intervenção pública } \\
\text { Servilismo }\end{array}$ \\
\hline $\begin{array}{l}\text { Reflexivo } \\
\text { Conhecimento } \\
\text { Verificação } \\
\text { Legitimidade } \\
\text { Prestação de contas } \\
\text { Política } \\
\text { Patologia }\end{array}$ & $\begin{array}{l}\text { Sociologia Crítica } \\
\text { Fundacional } \\
\text { Normativa } \\
\text { Visão moral } \\
\text { Aos intelectuais críticos } \\
\text { Debate interno } \\
\text { Dogmatismo }\end{array}$ & $\begin{array}{l}\text { Sociologia Pública } \\
\text { Comunicativo } \\
\text { Consensual } \\
\text { Relevância } \\
\text { Aos públicos designados } \\
\text { Diálogo público } \\
\text { Modismo passageiro }\end{array}$ \\
\hline
\end{tabular}

Fonte: Braga e Burawoy ${ }^{19}$. 
da", que procura iluminar os elos existentes entre os problemas privados e os desafios públicos, a partir da centralidade axiológica dos conhecimentos dos subalternos. Trata-se, antes de tudo, de um "estilo", na medida em que supõe uma maneira de escrever e de se comunicar com diferentes públicos, além de supor, também, uma modalidade determinada de engajamento intelectual.

A Sociologia Profissional e a Sociologia para Políticas Públicas (ou Aplicada) orientam-se para resolver problemas sociológicos e/ou sociais, sendo a primeira considerada acadêmica e desenvolvida principalmente na interseção de programas de pesquisa com suas pressuposições, modelos, questões próprias, aparatos conceituais e teorias em desenvolvimento, voltadas para solucionar problemas característicos que vêm de anomalias externas ou de contradições internas ${ }^{19}$.

A Sociologia para Políticas Públicas, também compreendida como Aplicada, compreende o subcampo das ciências sociais aplicadas à saúde como um exemplo. O autor vê pouca importância nesse ramo da sociologia e, como afirma Schwartzman ${ }^{18}$, não há dúvida que ele vê a sociologia aplicada como menos digna que as outras. Trata-se, portanto, segundo Burawoy ${ }^{17-19}$, de uma sociologia extra-acadêmica, a serviço de objetivos definidos por um cliente, com forte dependência da Sociologia Profissional, porém produzindo conhecimento "prático" e "útil”, legitimado pela sua eficácia, potencial de intervenção e satisfação dos clientes. Por fim, salienta que a Sociologia Aplicada é facilmente capturada por estes últimos, os clientes, que impõem obrigações contratuais rígidas nos seus financiamentos, distorcendo o seu alcance.

\section{O ensino das ciências sociais no campo da saúde: desafios e perspectivas}

De acordo com Bloom ${ }^{21}$, enquanto no início do século XX, principalmente devido à influência do Relatório Flexner, ocorreu a introdução das ciências biológicas básicas no currículo médico, nas décadas de 1940 e 50, respectivamente, foram introduzidas as ciências do comportamento psicológico e as ciências do social. Ainda segundo Bloom ${ }^{21}$ a emergência das ciências sociais no campo da saúde ocorreram pelo: desenvolvimento geral da ciência e necessidade de compreensão mais integral dos eventos da saúde; desenvolvimento de mais controle sobre os aspectos biológicos da doença; a crescente maturidade das ciências sociais; e a Segunda Guerra Mundial que disparou interesse intensificado da medicina na ci- ência social. Em relação à influência da guerra para a introdução das ciências sociais no campo da saúde nos Estados Unidos, Bloom ${ }^{21}$ afirma que foi um processo em cadeia: a medicina tornou-se mais interessada em psiquiatria; a psiquiatria desenvolveu crescente colaboração com as ciências sociais; as ciências sociais desenvolveram métodos de investigação e novos conhecimentos que permitiram uma convergência de seu trabalho com a psiquiatria e as profissões de saúde como um todo.

Sabe-se, também, que na mesma década de 1950 teve início o debate sobre o ensino da medicina preventiva e social e nela a participação das ciências sociais, ampliando-se o campo da pesquisa destas aplicadas à saúde, principalmente com investigações sobre o estudante de medicina em relação ao seu papel social e processo de profissionalização $\mathrm{O}^{22-24}$.

Nos anos de 1960 iniciou-se o importante movimento de aproximação das linhas de pesquisa da educação médica e ciências sociais aplicadas à saúde ${ }^{25}$. No entanto, desde aquele período sabe-se, também, que existem algumas dificuldades de aceitação das ciências sociais, como mostrou Garcia ${ }^{26}$ em relação: ao baixo status profissional em que os médicos vêm os cientistas sociais; localização pouco clara dos cientistas sociais na estrutura administrativa; e pequena importância atribuída pelos estudantes. Para Peters e Litva ${ }^{27}$, porém, apenas nos últimos anos ocorreu uma mudança de status do ensino das ciências sociais nos cursos da área da saúde, e esta valorização recente sinaliza, por um lado, o processo intenso de mudanças sociais associadas ao processo de saúde-doença-cuidado, mas, por outro, deixa ver um atraso histórico de décadas ao longo do século XX, uma vez que o Relatório Flexner, em 1910, já anunciava a necessidade de uma perspectiva socialmente orientada para a formação e trabalho médico ${ }^{12,28}$.

A necessidade das ciências sociais na educação em saúde é justificável pela relação de confiança entre cientistas sociais e médicos, construída ao longo do século XX, de forma que estes últimos passaram a encaminhar questões dos problemas sociais relativos à prestação dos serviços de saúde aos primeiros, considerados capazes de "prescrever" soluções científicas para problemas associados à prática da medicina científica $^{12}$. Ao mesmo tempo, mudanças populacionais intensificaram a necessidade de compreensão do impacto dos determinantes sociais na saúde, entre eles, principalmente, a mudança do perfil demográfico e epidemiológico das diversas 
populações mundiais. Com base nesta relação de confiança, intensas transformações demográficas e movimento de valorização recente, é possível visualizar elementos específicos da contradição do ensino das ciências sociais na educação no campo da saúde na atualidade.

\section{As ciências sociais são uma área tradicionalmente difícil de ser ensinada nos cursos de graduação da saúde}

Para Cockeham ${ }^{29}$, a década de 1950 é considerada a "Fase de Ouro" da sociologia da saúde, na qual cientistas sociais passam a ensinar e pesquisar temas relativos ao campo da saúde. Segundo Straus ${ }^{15}$ houve dois tipos de contratações de cientistas sociais pelas escolas médicas: uma que trazia o profissional para se integrar ao corpo de docentes de maneira integral e permanente e outra que "contatava" cientistas sociais de outros departamentos ou instituições para ministrar disciplinas ou tópicos no curso médico. Muitas escolas médicas ainda optam pela "contatação" e mesmo as que "contratam" priorizam pouco este profissional, como relata Peters e Litva ${ }^{27}$, para quem não é pouco raro encontrar escolas médicas e de outras categorias da saúde empregando apenas um ou menos que um professor em tempo integral para ser o responsável por desenvolver, oferecer e avaliar disciplinas de ciências sociais em todos os anos do currículo. Benbasant et al..$^{30}$ concordam e afirmam que as consequências são muitas e persistentes, inclusive levando à extinção de disciplinas quando o responsável aposenta-se ou muda de instituição.

Outro fenômeno associado à contratação precária é o ensino de ciências sociais por profissionais com pequena formação. Para compreender o processo de trabalho de especialistas e não especialistas em ciências sociais no campo da saúde, Litva e Peter ${ }^{28}$ conduziram investigação em 31 escolas de medicina do Reino Unido, em meados da década de 2000. Obtiveram retorno de profissionais de 29 escolas, sendo 41 especialistas em ciências sociais (31 sociólogos e 10 antropólogos), 22 especialista em ciências do comportamento (psicólogos) e 28 não especialistas que ensinam ciências sociais. Em relação ao vínculo institucional, concluíram que dos 91 profissionais participantes, 52 eram contratados por departamentos de psiquiatria e atenção primária, 8 por departamentos de educação médica, 23 departamentos de psicologia e sociologia, 7 departamentos de enfermagem e 1 contratado do "National Health Service".

As autoras concluíram, ainda, que especialistas e não especialistas têm visões muito seme- lhantes em relação aos conceitos de ciências sociais que devem ser ensinados a estudantes de medicina. No entanto, apontaram, enfaticamente, a importante diferença em relação à perspectiva do ensino deste conteúdo e o reconhecimento do valor da teoria, maior para especialistas que para não especialistas. Fato que para as autoras revela falta de conhecimento de base teórica e necessidade pragmática de conteúdo com aplicação prática explícita por parte dos "não especialistas"28. As autoras não definiram exatamente o que identificaram como "aplicação prática explicita", no entanto é bastante provável que seja da ordem da relação entre "algodão e conceito", que tratamos anteriormente.

Além disso, as autoras concluíram que as ciências sociais na educação médica, que generalizo para outras carreiras do campo da saúde, são relativamente recentes e que os profissionais que as realizam sofrem com o pequeno desenvolvimento de redes sociais formais da categoria. Sobretudo, quando esta falta implica em trabalho extra, em relação ao que o profissional tem que dominar de maneira especializada no campo das ciências sociais e da saúde. Há, também, sobrecarga de trabalho produzida pelas demandas complexas de suporte para a prática clínica, que exige competência e habilidade do cientista social para comunicar a relevância das ciências sociais para estudantes, professores e administradores.

Explica Sennet ${ }^{31}$ que existem dois tipos de limites, o de fronteira e o de divisa. A diferença entre eles é que "a divisa é um limite relativamente inerte; a população se rarefaz e é pequeno o nível de trocas; uma fronteira é um limite mais ativo (...) uma zona de intensa atividade". Para Santo ${ }^{32}$ habitar uma fronteira significa: fazer uso seletivo e instrumental das tradições trazidas por diferentes agentes; inventar novas formas de sociabilidade; lidar com hierarquias fracas e uma pluralidade de poderes e ordens jurídicas; manter a fluidez das relações sociais; e misturar heranças e invenções. Portanto, a sobrecarga a que se referem Litva e Peters ${ }^{28}$ é da ordem da condição fronteiriça.

O princípio de que é preciso ensinar ciências sociais ("need-to-know principle"), também utilizado para compor documentos brasileiros, como as Diretrizes Curriculares Nacional ${ }^{33}$, foi tomado por Satterfield et al.$^{34}$ para analisar a implementação das ciências sociais em cursos de medicina nos Estados Unidos. Ao concluírem que se trata de uma participação ainda pouco consistente, buscaram identificar o currículo mínimo de ciências sociais para a educação médica, o que também pode ser generalizado para outras 
carreiras do campo da saúde. Os autores construíram o "currículo ideal" e identificaram quatro principais dificuldades para desenvolve-lo: a) dificuldade de inserir conteúdo "novo" no currículo completamente lotado; b) dominação da cultura biomédica, cujo questionamento ameaça a própria instituição; c) inadequação de suporte e desenvolvimento de especialistas em ciências sociais pelas instituições; e, d) inserção das ciências sociais entre as chamadas "ciências básicas", quando é melhor compreendida por estudantes em treinamento clínico.

Também, a partir do princípio da necessidade das ciências sociais na educação médica, Barros e Spadacio $^{35}$ analisam desafios no Brasil, discutindo as contradições entre um campo do conhecimento que pretende alcançar "a todos os povos, a todos os tempos", por meio de um diálogo que promova a construção de autonomia e sentidos universalizantes, e outro campo que "consome" conhecimento, para intervir e controlar a vida individual e coletiva, também em sentido universalizante. Montagner ${ }^{36}$ também discute o potencial e as dificuldades da posição de interface das ciências sociais na saúde e conclui que elas têm um largo caminho, pois "se a saúde pública é relativa à saúde do povo, então há muito mais coisas envolvidas além da medicina”.

Briceño-Léon et al. ${ }^{37}$ analisaram o desenvolvimento das ciências sociais a partir da medicina social na Venezuela e encontraram muitas dificuldades, principalmente relacionadas ao compartilhamento do conhecimento básico e geral das ciências sociais com pessoas formadas em outras áreas. Os autores afirmam sumarizando que a incorporação teve caráter marginal em todo o currículo acadêmico e tendência teoricista com pouco vínculo com atividades de campo ou estágios para os alunos, além de uma reputação pobre entre os estudantes e professores.

O caráter marginal das ciências sociais no currículo é discutido por Beagan ${ }^{38}$ que salienta que, ainda que os temas sejam introduzidos não há garantia da incorporação dos seus conteúdos pelos estudantes. O autor comparou os resultados da investigação realizada com alunos de diferentes turmas do terceiro ano do curso de medicina e concluiu que, em sua maioria, eles não reconhecem e, às vezes, até negam, a importância da etnia, classe, gênero e orientação sexual para a compreensão do processo saúde-doença-cuidado.

Observa-se que são várias as dificuldades de integrar e ensinar ciências sociais nos cursos da área da saúde. No entanto, é mais espantoso o fato de que se trata de um conjunto de questões antigas, identificadas nos anos 50 e 60 do século
$X X$, que persistem inalteradas em uma estrutura que passou por intensas transformações ao longo do período.

\section{O contexto sociomédico é sempre subdesenvolvido e sua implementação é frequentemente impedida}

A diferença entre a perspectiva sociomédica e a médico-social mostra que a ordem dos fatores altera o produto. A primeira tem sido construída por cientistas sociais e humanos "na" e "da" medicina em busca de desenvolver explicações multicausais em suas análises, historicizando os eventos para delinear as forças sociais no processo de construção social da realidade em foco. Por outro lado, a abordagem médico-social, ainda que avance muito em relação às reduções promovidas pelo modelo biomédico, tem base lógica intervencionista e prescritiva, mesmo sob a orientação do discurso de prevenção e promoção da saúde. De outra maneira, o que se identifica é a diferença entre a compreensão e a análise, na medida em que compreender é ir além da identificação das estruturas, para historicizar referências socioculturais que constituem os fenômenos e que não se reduzem às exterioridades materiais e simbólicas ${ }^{39,40}$.

Para Minayo et al. ${ }^{41}$, o problema parece ser da ordem da dificuldade de integração de conhecimentos e a cisão entre natureza e cultura produzida na raiz do desenvolvimento da ciência moderna $^{42}$. Esta separação foi responsável pela redução da importância das condições históricas, geográficas e sociais do processo saúde-doença-cuidado para o pensamento epidemiológico, levando à incorporação das categorias das ciências sociais de maneira ideológica, no sentido de tomar a vertente marxista como a totalidade da "ciência social", ou instrumentalizada, de forma que as categorias sociais aparecem reificadas e como entidades com existência em si mesmas. Por outro lado, a incorporação de conceitos e categorias da epidemiologia pelas ciências sociais tem tornado a segunda refém da quantificação, sem torná-la mais científica, e sim pífia, na medida em que realiza estudos tecnicamente corretos, porém socialmente irrelevantes ${ }^{41}$. Concluem as autoras que existem potencialidades na interfertilização da epidemiologia pelas ciências sociais e vice-versa e, também, dificuldades de ordem conceitual, metodológica, histórica, cultural e até emocional.

Outro aspecto significativo que dimensiona o menor desenvolvimento da perspectiva sóciomédica é a avaliação negativa dos estudantes que normalmente afirmam não perceber a relevância 
das ciências sociais para a prática clínica. Para a maior parte deles a forma autorreflexiva de abordagens das ciências sociais entra muitas vezes em conflito com protocolos técnicos de outras disciplinas, que em geral são prescritivos e reproduzidos "acriticamente" ${ }^{40,43}$. Por isso, aponta Terva$\operatorname{lon}^{39}$, que existe grande potencial conflitivo do ensino de temas associados ao conceito de cultura na escola médica: primeiro, quando encoraja os estudantes a identificar a influência da sua identidade cultural na formação do seu sistema de crenças e observar o potencial de conflito que suas crenças disparam nos serviços de saúde; segundo, ao estimular os estudantes a identificar potenciais vieses, preconceitos e discriminação nas suas interações com colegas, profissionais e usuários, em diferentes cenários de práticas; e terceiro, quando os alunos são impulsionados a manter sua perspectiva crítica e reflexiva, como parte de seu compromisso ético-político, para a construção de um cuidado mais humanizado, integral e universal.

Também para Benbasant et al. ${ }^{30}$ a avaliação dos estudantes é uma das maiores barreiras para a perspectiva sociomédica no curso de medicina, pois os estudantes identificam a relação entre os determinantes sociais e psicológicos na saúde como óbvios e, por isso, afirmam não necessitar aprofundamento. Os autores discutem como os alunos demonstram-se desinteressados pelas informações que acreditam importantes e rejeitam "preconceituosamente" as informações que julgam irrelevantes. O efeito do posicionamento dos estudantes leva a dois fenômenos: um mais recente e referente à reinstalação dos profissionais das ciências sociais em instituições de ensino e pesquisa de ciências sociais e humanas, fazendo crescer a sociologia "da" saúde em detrimento da sociologia "na" saúde. Sobre este êxodo, Benbasant et al..$^{30}$ discutem que os cursos de ciências sociais nas faculdades de medicina de Israel foram iniciados e desenvolvidos por sociólogos e antropólogos, que aos poucos foram sendo substituídos por não especialistas. O outro fenômeno relaciona-se à mudança permanente dos conteúdos e técnicas pedagógicas das disciplinas de ciências sociais. A revisão constante dos conteúdos é parte do exercício de ajustamento ao interesse dos estudantes e necessidades da prática clínica, por outro lado, cria uma dificuldade relativa à multiplicação de abordagens e temas, que confundem as prioridades do que deve ser ensinado.

Assim, a dificuldade da perspectiva sociomédica no ensino no campo da saúde deve-se, além da diversidade de temas, à dificuldade de cientis- tas sociais e profissionais de saúde em desenvolverem integração horizontal e vertical no currículo. No entanto, para Benbasant et al. ${ }^{30}$, o que ocorre desde o início do ensino de ciências sociais na medicina é um distanciamento que cria, além dos conflitos entre "nós e eles", certos posicionamentos que dificultam a integração. Para ilustrar, os autores citam o trecho de uma das entrevistas, realizada em 1981 com chefes de Departamento de Clínica e Medicina de Família de escolas médicas norte-americanas, que declara: "é perigoso deixar sociólogos nas escolas médicas... eles causam divisões, enfatizando as diferenças nos cuidados ao invés de pontos em comum" ${ }^{\text {"30 }}$. Discursos de médicos que mostram menosprezo pelas ciências sociais não parecem ser incomuns e Briceño-Leon et al. ${ }^{37}$ também trazem seu exemplar venezuelano, "em medicina há muitas situações em que o social, que embora nunca deixe de ter importância, em um determinado momento não constitui o fato fundamental que o médico deve cuidar, porque a cura é, então, o que realmente importa".

Portanto, desenvolver o contexto sociomédico em instituições do campo da saúde não é fácil, sobretudo porque, na maioria das vezes, como destacam Litva e Peters ${ }^{28}$, os entraves são reproduzidos de maneira "invisível" no currículo oculto das escolas, moldando símbolos e valores nos discursos e nas ações das novas gerações, estabelecendo fronteiras, limites e grande dificuldade de legitimidade.

\section{Considerações Finais}

Embora reconheça as importantes contribuições de Buroway ${ }^{17,19} \mathrm{em}$ sua análise sobre os tipos de sociologia, considero que seu olhar é de um analista externo ao que se coloca centralmente sobre as ciências sociais no campo da saúde. Sobretudo, pelo fato de que ele opera polarizando conhecimentos, quando o que mais nos permite compreender os desafios e as perspectivas das ciências sociais em sua aproximação com as ciências da saúde é a ambivalência de pertencer a um campo do conhecimento sem existir em seu núcleo estrutural e ocupacional.

Certamente as ciências sociais aplicadas à saúde aproximam-se em muito da chamada "Sociologia Pública”, que busca engajar múltiplos públicos e caminhos no debate de questões sociais. Porém, o interesse da maior parte dos profissionais de saúde de incrementar o ensino das ciências sociais parece estar mais relacionado às suas 
dimensões pragmáticas e interventoras, e menos à sua potência de aplicação "pública", isto é, de incrementar o diálogo público e comunicativo com diferentes atores envolvidos no processo saúde-doença-cuidado.

Assim, aos profissionais das ciências sociais aplicadas à saúde ainda é colocada a necessidade de explorar a sua identidade ambivalente, tanto entre cientistas sociais, quanto entre profissionais da saúde, embora o campo das ciências sociais aplicadas à saúde já tenha se especializado, por exemplo tornando-se sociologia da saúde e antropologia da saúde, e exista há mais de seis décadas.

Para Straus ${ }^{15}$, que fez o primeiro levantamento do ofício dos sociólogos na saúde, os profissionais, ao se disporem a trabalhar no campo da saúde, deveriam adotar as estratégias de um camaleão, pintando-se das cores predominantes no ambiente para aumentar suas chances de sobrevivência. Em suas palavras, os cientistas sociais no campo da saúde "como o camaleão, [que] tem uma estrutura de base e uma integridade básica que não variará", devem saber que a "sua adaptação ao ambiente pode depender de uma capacidade para alterar certas manifestações externas em conformidade com o meio ambiente" 15 .

Nos anos de 1980 esse debate volta à carga com Hans Mauksch ${ }^{44,45}$, quando toma a dianteira do processo de criação da rede de professores de ciências sociais da Associação Americana de Sociologia, agregando valor e legitimidade para o trabalho pedagógico no campo da saúde. A centralidade do pensamento de Mauksch está nas premissas que criou para orientar o ensino das ciências sociais para profissionais de saúde: primeira, os cientistas sociais devem garantir clareza conceitual e organizacional sobre as fronteiras do campo da saúde e das humanidades, para conseguir priorizar as ciências sociais incluindo outros saberes; segunda, a valorização do ensino das ciências sociais no campo da saúde depende de ampliar o conteúdo do campo para incorporar o maior número possível de forças sociais relevantes; terceira, é preciso diversificar as técnicas e os métodos de ensino e pesquisa, para maximizar a perspectiva social do processo de saúde-doença-cuidado ${ }^{44,45}$.

O que ambos os autores mostram é que a sobrevivência em um ambiente socialmente inapropriado ou "não natural" exige estratégias específicas, as quais, como se viu anteriormente, muitas vezes, apresentam-se de forma invisível e quase sempre sobrecarregam os profissionais submetidos a elas. $\mathrm{Na}$ perspectiva pós-colonial de Bhabha ${ }^{7}$ trata-se de um exercício de mímica, que, muitas vezes, corre o risco de se perder no arremedo alienado e inoperante. Segundo o autor, a mímica emerge como a representação de uma diferença que é ela mesma um processo de recusa, sendo o signo de uma articulação dupla, uma estratégia complexa de reforma do inapropriado, onde o excesso ou o deslocamento produzido pela ambivalência da mímica (quase o mesmo, mas não exatamente) não apenas rompe o discurso, mas se transforma em uma incerteza que fixa o sujeito colonizado como uma presença parcial, incompleta e virtual ${ }^{7}$.

A construção das profissões da saúde como ciência do social está apontada há mais de um século e meio por Rudolf Virchow ${ }^{46}$. No entanto, Monrouxe e Rees ${ }^{47}$ mostram que este debate ainda não foi adequadamente desenvolvido e a perspectiva natural predomina sobre a social, de maneira hegemônica, porém não homogênea, na educação de profissionais de saúde. Para os autores, esta é uma barreira estrutural para a integração temática e pedagógica das ciências sociais no campo da saúde, uma vez que elas são consideradas "ciências soft" frente aos requisitos das "ciências hard". Todavia, estamos seguros de que não se trata de escolher uma perspectiva em detrimento da outra, mas garantir que ambas colaborem para desenvolver conhecimento menos parcial e incompleto.

Além disso, é preciso construir valores e símbolos positivos para o conhecimento que se considera fruitfull unrelated and irrelevant na educação de profissionais de saúde, que são, segundo Borleffs ${ }^{48,49}$, disciplinas das ciências sociais que tratam da filosofia da ciência, história da medicina, literatura e sociologia. De acordo com o autor, estes são conhecimentos considerados não relevantes para problemas práticos do campo da saúde e de interesse teórico apenas; considera, ainda, que não existem e possivelmente não existirão estudos controlados que mostrem evidências científicas da adição de valores com o ensino das ciências sociais.

No entanto, a sociedade como um todo pede, com urgência, a humanização das interações e, mais ainda, o fim do projeto colonizador de saberes no campo da saúde, com sua estratégia de nomear a diferença como uma proliferação de objetos inapropriados. Por isso, nosso propósito neste artigo não buscou trazer respostas diretas sobre como solucionar as contradições entre o aplicado e o teórico no ensino das ciências sociais em saúde. Mas apontar algumas dificuldades que tendem a se dissipar, na medida em que 
ocorra a redução e a substituição do processo reificador, ainda central no modelo de cuidado atual como resultado da naturalização do "reino social”, pela apreensão do processo de saúdedoença-cuidado como produto sócio-historicamente construído.

\section{Referências}

1. Bourdieu P. Questões de sociologia. Rio de Janeiro: Ed. Marco Zero; 1983

2. Bourdieu P. O poder simbólico. Rio de Janeiro: Bertrand Brasil; 2000.

3. Bourdieu P. Coisas Ditas. Rio de Janeiro: Brasiliense; 2004.

4. Bourdieu P. A Distinção social - Crítica social do julgamento. São Paulo: Zouk; 2007.

5. Pinto L. Pierre Bourdieu e a teoria do mundo social. Rio de Janeiro: FGV; 2000.

6. Silva HR. A gênese da sociologia crítica de Pierre Bourdieu. Rev. Espaço Acadêmico 2010; 112:114-120.

7. Bhabha HK. O local da cultura. Belo Horizonte: Ed. UFMG; 2003.

8. Souza LMTM. Hibridismo e tradução cultural em Bhabha. In: Abdala Júnior B, organizador. Margens da cultura: mestiçagem, hibridismo \& outras misturas. São Paulo: Boitempo Editorial; 2004. p. 113-133.

9. Zingerevit WJ. Georges Canguilhem - o centenário de nascimento do 'médico-filósofo' francês. Revista Cult. 2002. [Internet]. [acessado $2014 \mathrm{fev} 22$ ]. Disponível em: http://www.paradigmas.com.br/ parad28/p28.8.htm

10. Diniz M. Neomarxistas e neoweberianos: sobre natureza do estrato profissional. Rio de Janeiro: Dados; 1996.

11. Weber M. Metodologia das ciências sociais. $3^{\text {a }}$ ed. São Paulo: Cortez; 2001.

12. Nunes ED, Hennigton EA, Barros NF, Montagner MA. O ensino das ciências sociais nas escolas médicas: revisão de experiências. Cien Saude Colet 2003; 8(1):209-225.

13. Kuhn T. A estrutura das revoluções cientificas. São Paulo: Perspectiva; 1987.

14. Barros NF. A construção da medicina integrativa: um desafio para o campo da saúde. $1^{\text {a }}$ ed. São Paulo: Hucitec; 2008.

15. Straus R. The nature and status of medical sociology. Amer Soc Rev 1957; 22(2):200-204

16. Turner BS. Medical power and social knowledge. London: Sage; 1995.
17. Burawoy M. Por uma sociologia publica. Política \& Trabalho Revista de Ciências Sociais 2006; 25:9-50.

18. Schwartzman S. A sociologia como profissão pública no Brasil. In: Dwyer T, Villas Boas G, Scalon C, organizadores. Consensos e controvérsias. Porto Alegre: Tomo Editorial; 2011. p. 119-130.

19. Braga R, Burawoy M. Por uma sociologia pública. São Paulo: Alameda; 2009.

20. Braga R, Santana MA. Sociologia pública: engajamento e crítica social em debate. Cad. CRH 2009; 22(56):223-232.

21. Bloom S. The doctor and his patient. A sociological interpretation. New York: Russell Sage Foundation; 1963.

22. Merton RK, Reader G, Kendall PL. The studentphysician: introductory studies in the sociology of medical education. Cambridge: Harvard University Press; 1957.

23. Becker HS, Geer B, Hughes EC, Strauss A. Boys in white: student culture in medical school. Chicago: The University of Chicago Press; 1961.

24. Nunes ED. As ciências sociais nos planos de estudo de graduação e pós-graduação. In: Nunes ED. As ciências sociais em saúde na América Latina: tendências e perspectivas. Brasília: OPAS, 1985. p. 427-458.

25. Badgley RF, editor. Ciencias de la conducta y enseñanza médica en América Latina. Nova York: Fundación Milbank Memorial; 1966.

26. Garcia JC. La educación médica en la América Latina. Washington: Organização Panamericana de la Salud; 1972.

27. Peters S, Litva A. Relevant behavioural and social science for medical undergraduates: a comparison of specialist and non-specialist educators. Med Educ 2006; 40(10):1020-1026.

28. Litva A, Peters S. Exploring barriers to teaching behavioural and social sciences in medical education. Med Educ 2008; 42(3):309-314.

29. Cockerham WC. Medical sociology at the millennium. In: Scambler G, editor. Medical Sociology major themes in health and social welfare. London: Routledge; 2005. 
30. Benbassat J, Baumal R, Borkan JM, Ber R Overcoming barriers to teaching the behavioral and social sciences to medical students. Acad Med 2003; 78(4):372-380.

31. Sennet R. Juntos. Rio de Janeiro: Record; 2012.

32. Santos BS. A crítica da razão indolente: contra o desperdício da experiência. São Paulo: Cortez; 2000.

33. Brasil. Ministério da educação e Cultura. Diretrizes Curriculares Nacionais. [site da Internet]. [acessado 2014 fev 22]. Disponível em: http://portal.mec. gov.br/cne/arquivos/pdf/Med.pdf

34. Satterfield JM, Adler SR, Chen HC, Hauer KE, Saba GW, Salazar R. Creating an ideal social and behavioural sciences curriculum for medical students. Med Educ 2010; 44(12):1194-1202.

35. Barros NF, Spadacio C. A formação do pós-graduando no mundo contemporâneo no cotidiano da pesquisa. Saude soc 2011; 20(1):50-56.

36. Montagner MA. Sociologia médica, sociologia da saúde ou medicina social? Um escorço comparativo entre França e Brasil. Saúde soc 2008, 17(2):193210.

37. Briceño-Leon R, García B, Rodríguez V, Tovar L. Las ciencias sociales y la salud en la modernización de Venezuela. Cien Saude Colet 2003; 8(1):63-77.

38. Beagan BL. Teaching social and cultural awareness to medical students: "it's all very nice to talk about it in theory, but ultimately it makes no difference". Acad Med 2003; 78(6):605-614.

39. Tervalon M. Components of culture in health for medical students' education. Acad Med 2003; 78(6):570-576.

40. Freidson E. Profissão médica: um estudo de sociologia do conhecimento aplicado. São Paulo: Editora UNESP; 2009.

41. Minayo MCS, Assis SG, Deslandes SF, Souza ER. Possibilidades e dificuldades nas relações entre ciências sociais e epidemiologia. Cien Saude Colet 2003; 8(1):97-107.

42. Czeresnia D. Epidemiologia, Ciências Humanas e Sociais e a integração das ciências. Rev Saude Publica 2008; 42(6):1112-1117.

43. Barros NF. As Ciências Sociais na Educação Médica [tese]. Campinas: Unicamp; 2013.
44. Weiss GL. A Pedagogical Boomerang: From Hans Mauksch to Medicine to the Teaching and Learning of Sociology. Teaching Sociology 2007; 35(1):116.

45. McCartney JL, Mauksch H. An Interview with Hans Mauksch. Teaching Sociology 1983; 10(4):419-461.

46. Santos MS. Virchow: medicina, ciência e sociedade no seu tempo. Coimbra: Imprensa da Univ. de Coimbra; 2008.

47. Monrouxe LV, Rees CE. Picking up the gauntlet: constructing medical education as a social science. Med Educ 2009; 43(3):196-198.

48. Borleffs JC. What is a good doctor? The impact of 'fruitful irrelevance' in medical education. Med Teach 2009; 31(5):447-448.

49. Petersdorf RG, Feinstein AR. An informal appraisal of the current status of "medical sociology. JAMA 1981; 245(9):943-950
Artigo apresentado em 01/06/2013

Aprovado em 22/08/2013

Versão final apresentada em 27/08/2013 
